\title{
Cloning and sequence analysis of hsf, an outer membrane protein gene of Pasteurella multocida serotype B:2
}

\author{
A. Priyadarshini, S. Kumar, S. K. Gupta, K. N. Viswas, R. K. Agarwal and V. P. Singh
}

Division of Veterinary Bacteriology, Indian Veterinary Research Institute, Izatnagar, Bareilly, Uttar Pradesh, India Corresponding author: A. Priyadarshini, email: adyashavet01@gmail.com, SK: skumar.cdri@gmail.com, SKG: skgupta15@rediffmail.com, KNV: vkn111@gmail.com, RKA: grace_bly@yahoo.com, VPS: vijendra61@gmail.com Received: 28-09-2014, Revised: 04-11-2014, Accepted: 09-11-2014 Published online: 15-12-2014

doi: 10.14202/vetworld.2014.1090-1093. How to cite this article: Priyadarshini A, Kumar S, Gupta SK, Viswas KN, Agarwal RK, Singh VP (2014) Cloning and sequence analysis of hsf, an outer membrane protein gene of Pasteurella multocida serotype B:2, Veterinary World 7(12): 1090-1093.

\begin{abstract}
Aim: The present study was undertaken to clone, sequence and analyze the $h s f$, an outer membrane protein gene of Pasteurella multocida serotype B:2

Materials and Methods: $h s f$ gene was amplified from genomic DNA of P. multocida. Polymerase chain reaction (PCR) product was cloned in pET-32a vector and was characterized. $h s f$ gene was sequenced, analyzed and phylogenetic tree was constructed taking sequences of other strains.
\end{abstract}

Results: Amplicon size was found to be $785 \mathrm{bp}$. Recombinant got characterized through colony PCR and restriction enzyme analysis.

Conclusion: hsf gene of P. multocida serotype B is similar to serotype A, but different from serotype D. Further work is needed to evaluate role of Hsf protein in protection studies and to study the antigenic properties of this recombinant protein as a candidate for vaccine.

Keywords: cloning, hsf gene, outer membrane protein, Pasteurella multocida, phylogenetic tree, sequencing

\section{I ntroduction}

Pasteurella multocida, a Gram-negative coccobacillus, non-motile, rod shaped, facultative anaerobic bacterium, is the causative agent of a various economically dreaded diseases such as hemorrhagic septicemia (HS), atropic rhinitis, fowl cholera, shipping fever, pneumonia and snuffles in various domestic and wild animals. P. multocida isolates are differentiated mostly basing on their capsular types (A, B, D, $\mathrm{E}$ and $\mathrm{F}$ ) and somatic serotypes (1-16) [1]. Organisms belonging to serogroup $\mathrm{B} / \mathrm{E}$ are responsible for a very fatal disease i.e. HS among the cattle population. Similarly, predominant fowl cholera strains belong to serogroup A [1], whereas strains causing diseases in swine (progressive atrophic rhinitis) belong to serogroup D [2].

HS is endemic in most tropical countries such as India and Africa causing high mortality in livestock [3]. A wide range of host such as cattle, buffalo, pig, sheep, goat, deer and camel are susceptible to this infection [4]. Though the uses of inactivated and live attenuated vaccines have led to a considerable reduction in overall livestock mortality, still the objective of complete protection has not been achieved [3].

Outer membrane proteins (OMPs) are involved in protective immunity against $P$. multocida infections. Virulence factors of $P$. multocida aid in the

Copyright: The authors. This article is an open access article licensed under the terms of the Creative Commons Attributin License (http:// creative commons.org/licenses/by/2.0) which permits unrestricted use, distribution and reproduction in any medium, provided the work is properly cited. colonization, invasion, and its pathogenesis are surface located [5].

OMPs have been reported to confer various virulence attributes of the organism like colonization and invasion thus, are potential antigenic candidates [6]. Therefore, identification of OMPs is critical to make out the protective antigens and to develop novel diagnostics after proper evaluation of their antigenic potential and the ability to contribute to the host immunogenicity. OMPs of P. multocida based on functional characteristics were categorized and have been shown to stage pivotal role in host pathogen interaction and disease processes [7]. The key antigens of $P$. multocida B:2 that evoke protective immunity to HS in cattle have still not been well defined. Although sequencing of genes encoding various OMPs has been carried out, still for many genes no study has yet been done.

The present study was aimed to characterize important OMP hsf, a high molecular weight auto transporter adhesion protein, is a virulence factor. No systematic study on sequence analysis of $h s f$ gene has been carried out till date, therefore, these proteins can be exploited for development of recombinant antigens based diagnostic test for detection of HS in bovines or as vaccine candidate for providing protection against the ailment.

\section{Materials and Methods}

\section{Ethical approval}

The Institutional Animal Ethics Committee (IAEC)/Committee for the Purpose of Control and Supervision of Experiments in Animals (CPCSEA) of 
the IVRI, Izatnagar had approved for immunization studies.

\section{Extraction of total genomic DNA of $P$. multocida serotype B:2}

Genomic DNA was extracted from culture of $P$. multocida serotype B:2 maintained in the Division of Bacteriology \& Mycology, Indian Veterinary Research Institute, Izatnagar by CTAB method and was preserved for further use.

\section{Polymerase chain reaction (PCR) amplification, clon- ing and its characterization}

hsf gene was amplified with PCR using primers with BamHI and SacI restriction enzyme sites (HSF-F/ Upper primer: 5'- CATATCggatccAATATTGCGAT TGGTGATGGT-3’ and HSF-R/Lower primer: 5'- G AATCGgagctcGTTTGTATTGCCTTTTGTATTTTT -3’) to amplify 785 bp amplicon from $P$. multocida genomic DNA. Primers were designed taking the reference sequence available at GenBank (AE004439.1).

The PCR was carried out in $50 \mu$ l reaction volume containing $10 \mathrm{pmol}$ of each primer, $0.1 \mathrm{mM}$ of dNTPs, $1.5 \mathrm{mM}$ of $\mathrm{MgCl}_{2}, 2 \mathrm{U}$ of vent polymerase (NEB, UK) in $1 \mathrm{X}$ reaction buffer using 50 ng of genomic DNA as template. The reaction conditions were as follows; initial denaturation $95^{\circ} \mathrm{C}$ for 5 min. 35 cycles denaturation at $94^{\circ} \mathrm{C}$ for $1 \mathrm{~min}$, annealing at $58^{\circ} \mathrm{C}$ for $1 \mathrm{~min}$, extension at $72^{\circ} \mathrm{C}$ for $1 \mathrm{~min}$ followed by one cycle of final extension at $72^{\circ} \mathrm{C}$ for $10 \mathrm{~min}$. The amplified products were analyzed by electrophoresis in 1.5\% agarose containing ethidium bromide $(0.5 \mu \mathrm{g} / \mathrm{ml})$.

The amplified PCR product and pET-32a vector were double digested with restriction endonuclease enzymes BamHI (Fermentas) and SacI (Fermentas) and ligated using T4 DNA ligase (Novagen, USA). Recombinants were screened through colony PCR using gene specific primers as given above and further analyzed by electrophoresis in 1.5\% agarose containing ethidium bromide $(0.5 \mu \mathrm{g} / \mathrm{ml})$.

Recombinant plasmid was also characterized through double restriction digestion analysis using BamHI and SacI. The digested products of recombinant plasmid were separated on $1.5 \%$ agarose gel.

\section{DNA sequence analysis}

The positive recombinant plasmid containing hsf gene fragments of $P$. multocida was sequenced using both forward and reverse primers of pET-32a vector. Sequence was analyzed and submitted to NCBI GenBank. P. multocida strains 3480 (CP001409.1), Pm70 (AE004439.1) and hsf gene of Haemophilus influenza (AJ277635.1) were retrieved from NCBI. Phylogenetic analysis and percent similarity/divergence were analyzed using Mega Align (DNASTAR, Madison, Wisconsin, USA) software.

\section{Results and Discussion}

The 785 bp amplicon size as visualized in agarose gel electrophoresis indicated the amplification of $h s f$ gene from the $P$. multocida genomic DNA
(Figure-1). PCR product cloned in pET-32a vector was characterized by both colony PCR and restriction enzyme analysis. Colony PCR upon gel separation gave amplicon size $\sim 785$ bp that indicated the presence of $h s f$ gene (Figure-2). Recombinant plasmids were also characterized by double restriction enzyme digestion analysis where release of insert of size $\sim 785$ bp confirmed the presence of the gene of interest in the recombinant plasmid (Figure-3). Sequencing results were analyzed and further submitted to NCBI GenBank (KM593283). Phylogenetic tree based on hsf nucleotide sequences of three strains of $P$. multocida (P-52, 3480 and Pm70) and one strain of H. influenza is indicated in Figure-4. The nucleotide alignment results of hsf gene of different strains of $P$. multocida taking $\mathrm{P}-52$ as reference strain revealed $96.8 \%$ homology and 2.3\% divergence from Pm70 (P. multocida serotype A:1 isolates from USA) strain whereas 75.6\% homology and 29.1\% divergence from strain

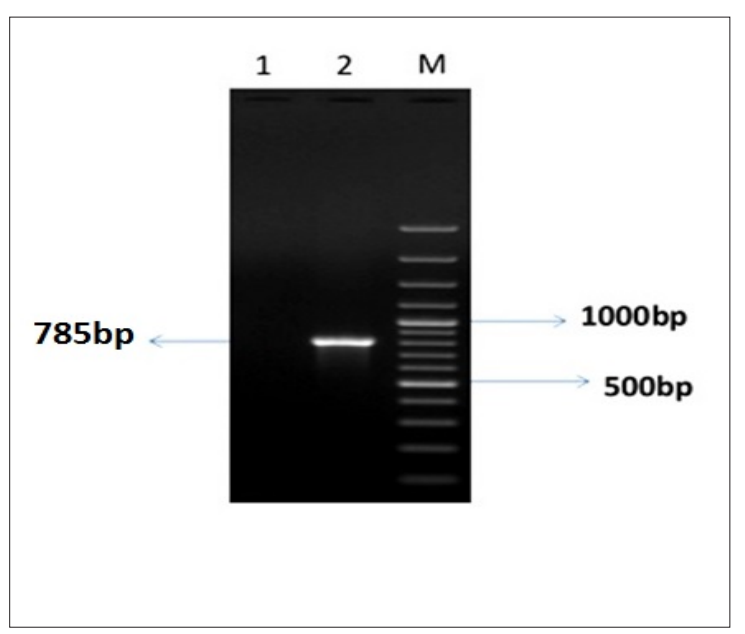

Figure-1: Polymerase chain reaction (PCR) amplification of $785 \mathrm{bp}$ hsf gene. The PCR product was analyzed in $1.5 \%$ agarose gel containing $0.5 \mu \mathrm{g} / \mathrm{mL}$ ethidium bromide. Lane 1: No Template Control; Lane 2: PCR product; Lane M: 100 bp ladder.

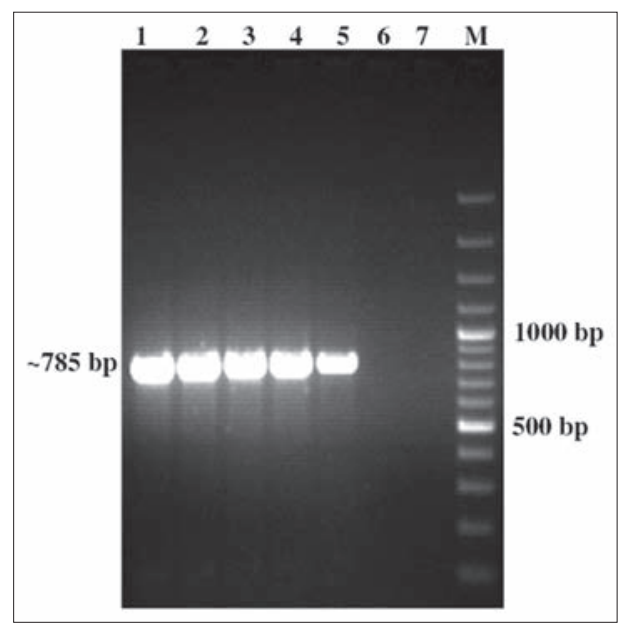

Figure-2: $1.5 \%$ agarose gel electrophoresis of colony polymerase chain reaction amplified using gene specific primers. Lanes 1-5: Recombinant clones; Lanes 6-7: Non recombinant clones; Lane M: 100 bp plus DNA ladder. 




Figure-3: Restriction endonuclease analysis of recombinant plasmid, Lane M: 100bp ladder, Lane 1: Undigested recombinant plasmid, Lane 2: BamHI and Sacl double digested recombinant plasmid

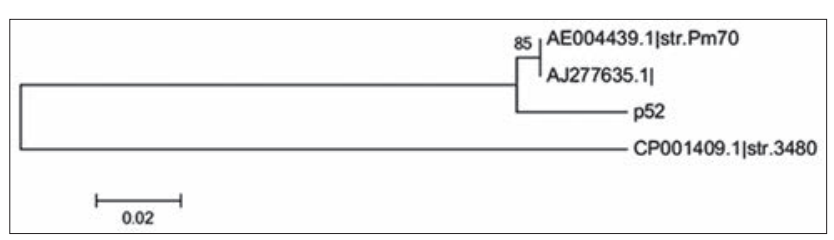

Figure-4: Phylogenetic tree based on nucleotide sequence illustrating the evolutionary relationship of hsf gene of P-52 strain with Pm70 (AE004439.1), 3480 strain (CP001409.1) of Pasteurella multocida and also with Haemophilus influenza (AJ 277635.1). The phylogenetic tree was constructed using neighbor-joining analysis. Numbers represent bootstrap values (given as percentages) for a particular node.

3480 (P. multocida serotype D isolates from China). Phylogram suggested that hsf gene of $P$. multocida serotype B is similar to serotype A, but different from serotype D. As only one isolate was sequenced, so it is not clear whether the substitution from serotype $\mathrm{D}$ observed in this study carry signature sequences for capsular type specificity or due to host origin specificity or for geographical location. $h s f$ is an adhesion related gene of $P$. multocida showed homology with $H$. influenza surface fibrils. The $H$. influenza type B Hsf is a vitronectin binding protein which contributes to resistance against antibody [8]. Transcriptional activation of $h s f$ gene of $P$. multocida was also found to be escalated under nutrient deficient conditions [9]. These above two findings suggested the role of $h s f$ gene in host resistance.

The $P$. multocida contains two types of $h s f$ gene namely $h s f 1$ and $h s f 2$. The frequency of $h s f$ gene varies among serotypes with the gene $h s f 2$ being more prevalent. In porcine isolates the $h s f 2$ gene is present in $99.1 \%$ isolates whereas $h s f 1$ in $67 \%$ strains [10]. Among Indian small ruminant isolates $h s f 2$ gene was present in $90.9 \%$ isolates whereas $h s f 1$ in $51.1 \%$ isolates [11].

The sequence analyses for many other genes encoding OMPs have showed variable degree of homology that was reported by several authors.
Recently, authors have reported that the vacJ gene had greater homogeneity (99.1-100\%) among the P. multocida strains [12]. Singh et al., 2010 [13] compared $p l p E$ gene in different capsular types and observed more than $90 \%$ homology whereas Siju et al., 2007 [14] observed $78.4 \%$ of similarity between nucleotide sequence of $p t f A$ gene in A:1 and B:2 isolates. Similarly Shivachandra et al., 2005 [15] reported 98.4\% homology and $1.5 \%$ divergence in $t b p A$ gene of $P$. multocida B:2 isolate from serotype A:1 isolates. Jain et al., 2013 [16] observed >95\% homology among $h a s R$ and $h g b A$ gene among different isolates. So this study highlights the need to exploit outer membrane genes and carry out multidimensional study in the field of diagnosis and prophylaxis.

\section{Conclusion}

HS is an important disease of cattle and buffaloes. For effective control of the disease, an efficacious and longer duration immunity vaccine is required. Identification and characterization of important immunogens of the bacteria would not only help in designing an improved vaccine but also Identification of the OMPs and exploiting it would serve as a candidate for development of diagnostics. As Hsf protein is one of the important virulence factors of the bacteria therefore further work is needed to evaluate its role in protection studies and to study the antigenic properties of this recombinant protein as a candidate for vaccine.

\section{Authors' Contributions}

AP carried out experimental execution, in-silico analysis, preparation of draft and revision of the manuscript. SK assisted in experimental executions. SKG and VPS participated in the conception and designing of experiment. KNV and RKA helped in trouble shooting during experiment and in the analysis of the final result.

\section{Acknowledgments}

Authors are thankful to Director, Joint Director (Acad/Res), Indian Veterinary Research Institure, Izatnagar, Bareilly for providing the necessary facilities and funding to carry out this work.

\section{Competing I nterests}

The authors declare that they have no competing interests.

\section{References}

1. Boyce, J.D., Wilkie, I., Harper, M., Paustian, M.L., Kapur, V. and Adler, B. (2002) Genomic scale analysis of Pasteurella multocida gene expression during growth within the natural chicken host. Infect. Immunol., 70(12): 6871-6879.

2. Davies, R.L., MacCorquodale, R., Baillie, S. and Caffrey, B. (2003) Characterization and comparison of Pasteurella multocida strains associated with porcine pneumonia and atrophic rhinitis. J. Med. Microbiol., 52: 59-67.

3. Shivachandra, S.B., Viswas, K.N. and Kumar A.A. (2011) A review of haemorrhagic septicaemiain cattle and buffalo. Anim. Health Res. Rev., 12(1): 67-82.

4. Sarangi, L.N., Thomas, P., Gupta, S.K., Kumar, S., 
Viswas, K.N. and Singh, V.P. (2014) Molecular epidemiology of Pasteurella multocida circulating in India by multilocus sequence typing. Transbound Emerg. Dis. doi: 10.1111/tbed.12270

5. Boyce, J.D., Cullen, P.A., Nguyen, V.I., Wilkie, I. and Adler, B. (2006) Analysis of the Pasteurella multocida outer membrane sub-proteome and its response to the in vivo environment of the natural host. Proteomics, 6(3): 870-880.

6. Lee, J., Kim, Y.B. and Kwon, M. (2007). Outer membrane protein $\mathrm{H}$ for protective immunity against Pasteurella multocida. J. Microbiol., 45(2): 179-184.

7. Hatfaludi, T.S., Al-Hasani, K., Boyce, J. D. and Adler, B. (2010) Outer membrane proteins of Pasteurella multocida. Vet. Microbiol., 144: 1-17.

8. Hallstrom, T., Trajkovska, E., Forsgren, A. and Riesbeck, K. (2006) Haemophilus influenzae surface fibrils contribute to serum resistance by interacting with vitronectin. J. Immunol., 177(1): 430-436.

9. Paustian, M.L., May, B.J. and Kapur, V. (2002) Transcriptional response of Pasteurella multocida to nutrient limitation. J. Bacteriol., 184: 3734-3739.

10. Tang, X., Zhao, Z., Hu, J., Wu, B., Cai, X., He, Q. and Chen, H. (2009) Isolation, antimicrobial resistance, and virulence genes of Pasteurella multocida strains from swine in China. J. Clin. Microbiol., 47(4): 951-958.

11. Sarangi, L.N., Thomas, P., Priyadarshini, A., Kumar, S., Viswas, K.N., Singh, V.P. and Gupta S.K. (2013) Virulence gene profiling and antibiotic resistance pattern of Indian isolates of Pasteurella multocida for small ruminant origin.
In: XXVII Annual Convention and National Conference of IAVMI-2013 on Productivity Enhancement through Improved Animal Health and Nutrition held at Lucknow, U.P. from December 13-15. p89.

12. Shivachandra, S.B., Kumar, A., Mohanty, N.N., Yogisharadhya, R., Chacko, N., Viswas, K.N. and Ramakrishnan M.A. (2014) Homogeneity of VacJ outer membrane lipoproteins among Pasteurella multocida strains and heterogeneity among members of Pasteurellaceae. Res. Vet. Sci., 96(3): 415-421.

13. Singh, A.P., Singh, S., Ranjan, R., Gupta, S.K., Singh, V.P. and Sharma, B. (2010) Molecular heterogeneity of plpE gene in Indian isolates of Pasteurella multocida and expression of recombinant PlpE in vaccine strain of Pasteurella multocida serotype B:2. J. Vet. Sci., 11(3): 227-233.

14. Siju, J., Kumar, A.A., Shivachandra, S.B., Chaudhuri, P., Srivastava, S.K. and Singh, V.P. (2007) Cloning and characterization of type 4 fimbrial gene (ptfA) of Pasteurella multocida serogroup B:2 (Strain P52). Vet. Res. Commun., 31(4): 397-404.

15. Shivachandra, S.B., Kumar, A.A., Amarnath, J., Joseph, S., Srivastava, S.K. and Chaudhuri, P. (2005) Cloning and characterization of tbpA gene encoding transferrin binding protein TbpA from Pasteurella multocida serogroup B:2 (strain P52). Vet. Res. Commun., 29: 537-542.

16. Jain, A. (2013) Expression and evaluation of diagnostic potential of recombinant outer membrane proteins of P. multocida serotype B: 2. M.V.Sc. Thesis Submitted to Deemed University, IVRI, Izatnagar, India. 